\title{
La experiencia sintomatológica: significación y resignificación del diagnóstico en tres casos de trastorno mental severo ${ }^{1}$
}

\author{
Elisa Alegre-Agís \\ DAFITS, Universidad Rovira i Virgili \\ elisa.alegre@estudiants.urv.cat
}

Resumen: A partir de los resultados de una etnografía llevada a cabo entre 2013 y 2014 en Barcelona y Tarragona, con pacientes diagnosticados de trastorno mental severo, se problematiza el diagnóstico de tres casos a partir de la significación subjetiva que las informantes hacen de la enfermedad y sus síntomas. Estos casos ponen de manifiesto tres niveles diferentes de relación paciente-síntoma-diagnóstico, y plantean las posibilidades/imposibilidades de actuar desde una resignificación de esa relación, evidenciando la experiencia corporal como un lugar hermenéutico y de reflexión. A partir de experiencias narrativas se recurre al concepto de dolor crónico propuesto por Byron Good para problematizar culturalmente la figura de enfermo total y de enfermedad ubicua en el marco de los trastornos mentales severos ${ }^{2}$.

Palabras clave: trastorno mental severo; síntoma; diagnóstico; cuerpo; dolor crónico.

Abstract: Based on results of an ethnographic study with patients diagnosed
with severe mental disorder done between 2013 and 2014 in Barcelona and
Tarragona, the diagnosis of three cases is considered from the subjective
meaning the patients make of the disease and its symptoms. These cases
present three different levels of patient-symptoms-diagnosis relation, and
1 Los datos y resultados de este artículo forman parte de la investigación «Una perspectiva antropológica al
principio de autonomía en pacientes diagnosticados de trastorno mental severo: el caso catalán», llevada a
cabo entre julio de 2013 y noviembre de 2014, coordinada por el Dr. Josep M. Comelles y financiada en el
marco de la beca de investigación del Institut Borja de Bioètica de la Universidad Ramon Llull, convocatoria
2013 .
2 Este texto se debe a la larga y entusiasta colaboración de mis informantes, a las que quiero agradecerles
especialmente su paciencia y participación. También a Martín Correa-Urquiza, Lucía Estrella Serra y Jordi
Marfa por abrirme las puertas en los espacios para el trabajo de campo, y a Josep Comelles por sus acertados
comentarios a los borradores de este texto. 
the possibilities/impossibilities of acting from a redefinition of this relation, revealing embodied experiences as explanatory and reflexive spaces. Based on these narrative experiences, I employ Byron Good's concept of «chronic pain» to culturally problematize the figure of the «total sick person» and the «ubiquitous illness» in the context of severe mental disorders.

Keywords‡ severe mental disorder; symptom; diagnosis; body; chronic pain.

\section{Del verbo corporalizado}

La categoría analítica de feeling-thinking ${ }^{3}$, recuperada de la etnoepistemología balinesa por Unni Wikkan, nos sirve como una dimensión para procesar la experiencia propia como conocimiento sedimentado en el cuerpo, y para la creación de conocimiento científico (DiGiacomo, 1995). El feeling-thinking nos remite a un fragmento anterior a la objetivación para trabajar desde lo que se denomina arco intencional ${ }^{4}$ (Carel, 2011), y que nos interesa como científicos sociales para reflexionar y analizar nuestro propio conocimiento a través de la experiencia.

Cuando comencé el trabajo de campo para mi trabajo final de máster, con personas diagnosticadas de trastorno mental severo (TMS) y sus familiares, me pregunté si aquello que yo había identificado en el plano de lo preobjetivo - como nieta de una persona diagnosticada ${ }^{5}$ - también podía encontrarlo

\footnotetext{
3 Para los balineses, las emociones no son emociones en nuestro sentido de la palabra. Para ellos, feeeling o sentir no se distingue de thought o pensar, sino que ambos son aspectos de un mismo proceso, keneh, lo que podríamos interpretar como feeling-thought. Ambos son racionales, ambos son subjetivos y ambos están en el dominio de la consciencia. La consciencia es la esencia del sentir-pensar; la experiencia se forma y los recuerdos se activan por la participación activa del feeling-thought (Wikkan, 1990). Por tanto, lo que la autora propone es diluir nuestra cultural ( $y$ antropológica) distinción entre emoción y pensamiento con el objetivo de ser capaces de comprender la cualidad de la experiencia vivida (Susan DiGiacomo, 2013).

$4 \mathrm{El}$ arco intencional es nuestra relación con el mundo en general. Una relación que incluye la intencionalidad del motor, pero también una estructura temporal, un entorno humano y una situación moral y existencial. Así, estos capturan la relación única que el ser humano tiene con el mundo, que no es solo física, sino que también está incrustada en un sentido cultural y cultual, lo que es, en última instancia, una situación existencial más que una mera posición física (Carel, 2011).

5 Haber convivido hasta los quince años con una persona diagnosticada en el espectro de las esquizofrenias me ha servido para hacerme preguntas a lo largo de mi investigación. Las primeras hipótesis que comencé a formular para mi tesis de doctorado se desprendían de curiosidades devenidas de mi experiencia. Concretamente, leyendo las etnografías del custodialismo sobre las dinámicas de las instituciones mentales. Muchas de las cosas descritas en estos textos se parecían a las formas de comportamiento que tenía mi abuela. Si bien mi abuela no tenía conciencia de enfermedad, ella solía describir sensaciones corporales cuando «se encontraba mal», muchas de ellas ligadas al espacio, otras veces a las personas que tenía alrededor, incluso a
} 
en mis informantes, entendiendo sus narrativas como experiencia vivida. Pensando en mis posibilidades como cuerpo-etnógrafo recaía en la idea de este como instrumento metodológico cuando se pone en acción en la interacción con los informantes. Mi investigación, centrada en la cotidianidad de personas afectadas de TMS y en sus problemas relacionales en el espacio doméstico, me hizo topar con narrativas que problematizaban la enfermedad mental como experiencia corporal.

Algunas narrativas explican la experiencia de la enfermedad mental desde una lógica corporal y emocional, como el sufrimiento asociado a las relaciones personales, los padecimientos devenidos del estigma, la idea de sujeto contaminante (Correa Urquiza et alii, 2006) o el riesgo (Lupton, 1999) percibido por la sociedad frente al loco.

Con este artículo pretendo hacer una aportación al campo de los estudios del cuerpo y de la salud mental. Tres casos me sirven para plantear diferentes formas de «corporalizar» el diagnóstico, de significarlo y reflexionarlo a partir de la experiencia de las protagonistas. Antonella, Irene y María del Mar nos muestran configuraciones diferentes del espacio corporal cuyo punto de comunión es una hermenéutica del cuerpo y la experiencia con la enfermedad mental en nuestro contexto cultural que conforma su mundo de vida.

\section{Sobre la etnografía ${ }^{6}$}

Este artículo forma parte de una investigación en el marco de la bioética llevada a cabo entre 2013 y 2014, y de mi tesis de doctorado en curso, cuyo objetivo es analizar las relaciones familiares del psicótico en el espacio doméstico. Los tres casos que se han seleccionado provienen del periodo en el que realizaba trabajo de campo (2013-2014) en un centro de salud mental ambulatoria (CSMA),

\footnotetext{
los objetos. Estas cuestiones, que de pequeña eran percibidas de un modo diferente, las fui analizando desde la perspectiva actual, siendo antropóloga y dedicándome a este tema de investigación. Así, leer a mi abuela desde este lugar me ha permitido generar preguntas y curiosidades hasta que, además, me topé con narrativas que explicaban cosas similares o equiparables a las que ella exponía. Es por ello por lo que esta investigación, en parte, surge desde esas sensaciones, percepciones e intuiciones que están «sedimentadas» en la experiencia corporal. Ideas, preguntas, hipótesis, que surgen de ese conocimiento previo a la objetivación y que es en un proceso de feeling-thinking que podemos convertirlo en el marco para la producción de conocimiento científico.

6 Los nombres de las informantes han sido cambiados con el fin de salvaguardar su anonimato. Asimismo, con el mismo fin de que no puedan ser identificadas, los datos sociodemográficos que se aportan de los informantes están limitados a aquellos estrictamente relevantes y pertinentes al análisis de este texto.
} 
dos espacios asociativos y una familia entre las provincias de Barcelona y Tarragona. En estos espacios se realizó observación —en el caso del CSMA y el espacio doméstico - y observación participante - en el caso de las asociaciones-. La técnica más utilizada ha sido la entrevista abierta, que se realizó tanto a personas diagnosticadas como familiares y profesionales. En algunos casos existieron conversaciones informales que resultaron piezas fundamentales para comprender los discursos de las entrevistas, y en el caso de la familia se realizaron grupo focales. En total se han llevado a cabo, hasta el momento, unas veinticinco entrevistas en profundidad entre profesionales, familiares $y$ personas diagnosticadas.

La etnografía en estos espacios permitió contemplar dimensiones de la vida cotidiana. Las entrevistas realizadas a pacientes y familiares versaron principalmente sobre la cotidianidad, las relaciones familiares, sociales y laborales, el estigma, la autopercepción y la concepción, entendimiento y simbolización subjetiva de los trastornos. Se realizó para cada uno de los afectados un recorrido biográfico y una trayectoria desde el primer brote o descompensación, procesos de internamiento, establecimiento del diagnóstico e itinerario terapéutico. Las entrevistas (entre tres y cinco por informante) se llevaron a cabo en diferentes espacios. En el primer caso se realizaron en cafeterías, además de haber compartido actividades vinculadas a la asociación y algunos encuentros informales en el que se tuvieron largas charlas; en el segundo caso se realizaron todas en el domicilio de la familia de origen, donde la informante ya no reside pero pasa buena parte del tiempo. En su caso, además, se realizaron dos grupos focales con los integrantes de la familia y algunas observaciones en el espacio doméstico; el tercer y último caso fue el de mayor número de entrevistas, cinco de manera formal y con grabadora, además de numerosos encuentros dentro y fuera de la asociación en la que nos conocimos. Estos casos se han seleccionado por ser los más representativos y significativos sobre el tema que tratar en este artículo.

\section{Cronicidad y cuerpo enfermo total}

El concepto de trastorno mental severo es un eufemismo que se utiliza para sustituir las connotaciones de los términos psicosis y cronicidad (Comelles y Martínez-Hernáez, 1994), derivado de los esfuerzos de unificación diagnóstica del DSM y el CIE-10 (APA 2013; OMS 1992). Desde la perspectiva del DSM-V, 
el espectro de las esquizofrenias y otros trastornos psicóticos son considerados prácticamente crónicos. El curso de estos trastornos es variable, con exacerbaciones y remisiones en algunos sujetos; se calcula que solo un $20 \%$ tiene un pronóstico más favorable, y que de estos solo unos pocos experimentan una remisión total de los síntomas (es decir, un retorno total al nivel premórbido) (APA, 2013: 86-122).

Desde el punto de vista médico, «la cronicidad se refiere a algo que continúa durante un tiempo prolongado. Una enfermedad crónica generalmente dura mucho tiempo y no desaparece en forma rápida o fácil» ${ }^{7}$. La dimensión social de la enfermedad (sickness) en nuestra cultura remite a variables que se articulan de forma muy variada en contextos específicos, como pueden ser modificaciones en la estructura, roles o significados de la familia o el grupo doméstico (París y Comelles, 1998). En mi investigación pude observar que la entrada de este tipo de diagnósticos genera una transformación en la estructura familiar, un conflicto entre los roles devenidos del parentesco y el «rol de enfermo»y, además, el diagnóstico es considerado por los miembros como una enfermedad crónica. La mayoría de las personas diagnosticadas y familiares entienden que es algo que no se cura y que las formas terapéuticas desde el sistema experto son solo paliativas y reductoras de los síntomas, sin lograr que estos desaparezcan del todo.

Por ello, para este análisis, considero necesario des-situar el trastorno mental del paradigma de la «incurabilidad» ligado al concepto de cronicidad; desubicarlo de su condición crónica en tanto «algo que no se cura» y trasladarla a la idea de «dolor crónico» que propone Good (1994). Desde esta perspectiva se entiende que la enfermedad se experimenta a través el cuerpo, y que este no es, como para el clínico, un objeto físico o estado fisiológico, sino una parte esencial del yo. El sufrimiento va más allá de lo meramente físico y se convierte en un fenómeno experiencial, sensación y emoción simultáneamente (Good, 1994).

La propuesta parece permanecer en el campo de la mera mutación semántica; sin embargo, el lenguaje es una forma de estar en el mundo, está embodied y es una ubicación experiencial (Csordas, 2002; 2004). Esto puede resultar un preludio para des-situar la patología entendida desde los paradigmas psiquiá-

7 Versión en inglés revisada por Linda J. Vorvick, A. (2015). Crónico(a): MedlinePlus enciclopedia médica. [online] Nlm.nih.gov. Disponible en: <https://www.nlm.nih.gov/medlineplus/spanish/ency/article/002312. htm $>$ [Consultado el 27 de diciembre de 2015]. 
tricos krapelinianos, poner en stand-by la categoría de enfermo, y des-enfermar al sujeto (Correa Urquiza, 2009) desde una perspectiva antropológica. Así, el dolor puede comprenderse como pre-objetivo y como agente (que tiene agencia) en un tránsito constante entre el everyday life-world y el pain-full world (Schütz, 1967): «El dolor crónico se convierte en un lenguaje en sí mismo que compite con el mundo cotidiano» (Jackson, 2004). Ir más allá de la categoría de enfermo crónico puede suponer actuar con ese dolor desde otros espacios fuera de la medicina, como propone la categoría de cronicidad de Masana, que incluye enfermedades y malestares que perduran en el tiempo, sean biomédicamente diagnosticadas o no (Masana, 2013).

Los etiquetados con TMS devienen en enfermos totales, puesto que el trastorno y sus significaciones impregnan su tejido vital. El sujeto deviene así en una suerte de enfermo absoluto que no solo lo está, sino que lo es en todas las instancias de su yo cotidiano (Correa Urquiza, 2009). Así, aquello que digan o hagan ya no es acertado ni verosímil, no tiene valor social; al sujeto, entonces, se le aplica un «tratamiento total» desde la idea de «enfermedad ubicua» ${ }^{8}$ que expresa la atribución al trastorno mental de toda conducta o acción realizadas por el sujeto, principalmente cuando hablamos de comportamientos que discrepan de nuestro punto de vista o que enjuiciamos como no pertinentes (Martínez-Hernáez, 2009).

Mi intención es poner de relieve algunas cuestiones que surgieron a lo largo del trabajo de campo que motiva la reflexión desde mi experiencia personal y profesional con la salud mental, rescatar el carácter interactivo entre la percepción, la reflexión y la acción como productora de resignificaciones y otras formas de vivir el trastorno mental, pensar un cuerpo que puede salirse de la apropiación experta y ser apropiado desde lo preobjetivo y lo profano más allá de cómo se haya simbolizado desde lo social y desde la institución social de la medicina. Hacer propios los cuerpos que habitamos, somos y hacemos puede

8 La metáfora de la enfermedad ubicua supone de forma casi invariable la atribución de una competencia nula o prácticamente inexistente a los afectados para desarrollar actividades que llevan a cabo sus conciudadanos y que están asociadas a una identidad social: ser trabajador, ser madre o padre, ser estudiante, ser miembro de una asociación civil, ser deportista, ser lector, ser voluntario, ser miembro de una agrupación de vecinos, ser - por qué no- miembro de un grupo religioso minoritario o de un colectivo a nuestros ojos exótico, ser, en definitiva, alguien socialmente hablando que no sea enfermo o usuario. La problemática del enfermo mental crónico es una cuestión de dignidad y de expectativas sociales. Su vida ha quedado desligada de aquellas identidades que le podían ofrecer un rol activo y una resignificación de su propia existencia. Así, las personas con trastorno mental severo no han adquirido un estatus que permita poner en positivo sus potencialidades (Martínez-Hernáez, 2009: 4). 
ser el matiz que permita que el «enfermo» actúe desde otras significaciones culturales del diagnóstico.

\section{El cuerpo como espacio hermenéutico: interpretación, significación y traducción}

\subsection{Antonella}

Antonella, de 25 años, diagnosticada de trastorno esquizofreniforme, cuenta que en su segundo brote estaba en un mundo muy feliz, en una realidad poética de introspección y creación artística. Una noche se sentó en la ventana del balcón de su casa:

[... ] Yo estaba sentada en el suelo, en el balcón de casa, en una ventana corrediza y tenía la mitad del cuerpo dentro y la mitad afuera... y sentía un montón de cosas de la mitad de la casa, un montón, en mi cabeza, en mi cuerpo, en todo, y un montón de cosas en la otra mitad... Ese día dije, Antonella, algo está pasando, cómo puede ser que estés sintiendo dos cosas completamente distintas, diferentes, en el mismo momento, en tu mismo cuerpo, en tu misma cabeza [...]. Eran cosas que me llegaban de un lado y del otro y que no tenían relación entre ellas, eran diferentes [...]. Cuando me asuste tomé consciencia, o sea, cuando me di cuenta de lo que pasaba, me asusté, hasta el momento solo era la percepción [...]. Sentía como que mi cuerpo y mi mente hubieran hecho un cortocircuito, $[\ldots]$ yo creo que desde entonces ha sido irreparable $[\ldots]$. Hay días en los que aparece un poco la Antonella de antes, pero en general no [...]. (Barcelona, enero de 2014)

Antonella tuvo una serie de sensaciones diferentes en relación con su posición en el espacio, un momento de ruptura que no le permitió volver a ser la misma; un antes y un después, una Antonella que se fue y que aparece a veces por «fragmentos». Mientras ella experimentaba dos sensaciones diferenciadas entre el adentro y el afuera, no tuvo miedo, hasta que «tomó consciencia». Cuando se dio cuenta de lo que estaba experimentando, cuando objetivó y simbolizó la experiencia como algo anormal, entonces interpretó en sus sensaciones preobjetivas que algo andaba mal y que tenía miedo:

[... Había momentos en que yo entraba en un lugar y me entraban dolores en la barriga fuertísimos... Salía de ese lugar, pasaba de esa habitación y ya no 
me pasaba más. Estaba en un aeropuerto cerca de alguien y estaba bien, me alejaba y me faltaba la respiración, no podía respirar, eran cosas físicas [...] no son puramente mentales, qué va, son cosas que te pasan en el cuerpo, tía. (Barcelona, enero de 2014)

[...] Era una hipersensibilidad a todo... Me hacía listas para hacer cosas con mi hermano pequeño. Cuando salí del hospital me las encontraba y eran todas ir al parque con Pau, hacer juegos con Pau. Entonces salía todo el día a la calle y no oía, pero sentía que Pau me decía, Antonella, vuelve a casa, y yo sentía la carencia de él, que me necesitaba... algo como superhumano [... . . (Barcelona, enero de 2014)

Antonella tiene una gran capacidad para describir y explicar lo que experimenta su cuerpo, interpretarlo y traducirlo en acción a partir de significaciones propias. Lee lo precultural y actúa a veces desde lo preobjetivo — cuando se deja llevar por su realidad poética-; otras, de acuerdo a la simbolización y significación que ella da a esas sensaciones, y, en otras ocasiones, de acuerdo a la significación construida desde los sistemas expertos. «No se trata solo de sensaciones mentales» me dijo, poniendo en evidencia un cuerpo que percibe, comprende y actúa en virtud de la interacción entre síntoma, diagnóstico y la experiencia vivida.

Antonella sedimenta en el cuerpo la información que experimenta y la lleva al mundo de vida, desde su cuerpo y con su cuerpo. Percibe, siente y se da cuenta cuando se está «descompensando». Esto es algo común en algunas personas diagnosticadas; sin embargo, ella considera que esas sensaciones son avisos de su cuerpo de que necesita un descanso y detenerse para oxigenarse. Por el contrario, muchas narrativas al respecto de detectar si se están descompensando versan sobre la intuición de que algunas cosas que suceden son «síntomas» propios de la enfermedad, como lo hace el sistema experto. Ella sabe perfectamente qué hacer: subir un poco su medicación, alejarse o suspender algunas actividades, avisar a los allegados que está «algo rayada» y que necesita un momento de ruptura; manifiesta que el sistema en el que vivimos no permite a las personas tener momentos de introspección y aislamiento momentáneo para explorarse a sí mismas.

Antonella realiza una descripción física de los síntomas y explica que suceden «en ella», remarcando una idea holística de su ser; al preguntarle si ubicaba 
las sensaciones en un lugar concreto, respondió que no habían pasado ni en su mente ni en su cuerpo, sino en su alma. La experiencia de las sensaciones y los dolores físicos resultan preobjetivos en tanto manifiesta no saber por qué le pasan o de dónde provienen. Simplemente suceden y suelen estar ligados a lo que la rodea, personas o espacios. Su cuerpo se extiende al espacio, a su habitación: [...] Estaba mi creatividad, ahí por todas partes, en las paredes, en la mesa, en la cama, en el suelo, estaba parte de mí ahí... Es eso de que es la prolongación de la persona, en lo que crea también, en lo que produce, en lo que es capaz de reflejar a través del arte o de la música, otros de yo qué sé, de lo que sea [...]. (Barcelona, enero de 2014)

Entiende sus prácticas teatrales como una prolongación de sí misma y se extiende más allá del cuerpo a través de su creación (acción). Las sensaciones que ha aprendido a interpretar, y que ha significado, le sirven para ponerse en movimiento, para actuar de un modo diferente, sentirse mejor. Hace caso de lo que el cuerpo le trasmite y no solo de los síntomas que el psiquiatra le ayuda a detectar, interpretar $y$, por tanto, actuar desde un modelo experto. Se ha apropiado de su cuerpo y se deja llevar por sus sensaciones. Encuentra formas de bienestar que se conectan con el feeling-thinking. Sentir y pensar simultáneamente lo que experimenta; poner en interacción dos entidades que solemos concebir por separado. Antonella se comunica e interacciona con el mundo de vida desde ese arco intencional que explicaba Carel, ese fragmento anterior a la objetivación y la simbolización. Piensa sus sensaciones actuando y actúa sensaciones traduciéndonos su interior a través de la acción. Recoge desde el feeling-thinking para actuar desde el arco intencional. Se agencia de aquello y lo simboliza fuera de la identidad de enferma. Podemos decir que Antonella ha podido salir de las entidades enfermo total o enfermedad ubicua en cierto modo. $\mathrm{Su}$ actitud y forma de entender el trastorno hace que no la interpretemos de forma constante como una enferma mental. Cuando le pedí que describiera lo que le pasa en los brotes o cuando no se siente bien, Antonella me interpeló aclarando que no es algo que pasa, sino que siempre es algo que pasó. Al acabar esos periodos, a pesar de que ya no es la misma desde aquel cortocircuito, Antonella sale del cuerpo enfermo para capturarlo y hacerlo suyo. 


\subsection{Irene}

Irene es ingeniera química, tiene 35 años y pareja estable. Su vida social es muy activa y tiene una familia que la sostiene y ayuda a gestionar su cotidianidad. Muy adepta al psiquiatra, la medicación y las citas suelen ser suficientes para no «ponerse mala». Sin embargo, a pesar de ser muy fiel a las indicaciones de su médico, Irene ha significado algunas cosas que siente fuera del modelo médico y recurre a terapias alternativas que le hacen mucho bien, pero que debe ocultar a su terapeuta.

Las sensaciones que Irene ha descubierto atraviesan su cuerpo y su mente como algo indivisible:

[... ] Lo que pasa es que si hago régimen me pongo mala, si lo hago muy heavy estoy más débil y entonces me suele pasar eso, que tengo pensamientos malos... Tu físico está más débil y tú te quedas más vulnerable y es como que te vienen los malos pensamientos recurrentes, de estos que tengo yo... porque la mente está como más débil también [...]. Si, porque estás más decaída y tal y entonces te pueden aparecer los síntomas de la esquizofrenia, las paranoias te atacan en ese momento [... ]. (Tarragona, febrero de 2014).

Si bien parece haber una relación entre la falta de alimentación y los delirios o las alucinaciones — casos de anacoretas, ayunos y su aparente relación con el éxtasis y la experiencia mística como estados alterados de conciencia ${ }^{9}$-, Irene no le ha comentado esta experiencia al psiquiatra porque recurre a una dietista naturista y a sesiones de hipnosis para adelgazar. Irene ubica lo mental y lo físico en un mismo plano, los pone en consonancia a partir de la experiencia de vulnerabilidad y debilidad vinculada a la dieta. Ha representado estos atributos como negativos, ya que provocan la aparición de los «malos» pensamientos que previamente habían sido simbolizados como síntomas de la esquizofrenia. La dieta pasa a ser reconocida y reflexionada como un fenómeno que va más allá del mero acto del control de la alimentación, y se proyecta al mundo de las «causalidades» en su experiencia. De esta manera, no se trata solo de un proceso por el cual perder peso, sino que forma parte del complejo sistema de relaciones entre ella, las alucinaciones, los delirios y la vulnerabilidad. Tal y como describe dicha interacción, estos «pensamientos malos» figuran un agen-

$9 \mathrm{Al}$ respecto, véase por ejemplo Rodríguez-Zafra (2007) o Melián (2014) en la bibliografía. 
te externo que la acecha, esperando a que su «fortaleza» baje la guardia para atacarla.

Irene dice que reconoce que tiene una enfermedad, pero que no se siente una enferma mental, concibe los síntomas de la esquizofrenia como algo ajeno, que no es producto de su cerebro o su mente, sino que acontece desde un afuera; una relación entre el exterior y el interior. Recuperando la concepción de Jackson del dolor, como ente con agencia propia, Irene parece significar de este modo sus síntomas o «pensamientos raros» que ejercen y actúan con independencia a partir de una condición dada como la dieta.

Al preguntarle acerca de la causa de su enfermedad, y en relación con su primer brote, Irene respondió:

[... ] Fue por el estrés, por forzar la máquina; estaba trabajando muchas horas, no dormía bien, tenía tres trabajos a la vez, y luego estudiando también, o sea... forcé la máquina, ya está. Y ahora ya sé que cuando hago esto, me pongo mala [...]. (Tarragona, febrero 2014)

Vuelve a ubicar el problema en un exterior y expresa lo que más le aqueja de la enfermedad mental:

[...] Pues los momentos de mucho estrés, pues sé que no puedo, no puedo, no valgo, no valgo... necesito dormir mis ocho horitas, tener una vida tranquila, no puedo hacer excesos, ni acostarme a la seis de la mañana [... no puedo beber alcohol, y a mí me encanta beberme una cervecita con alcohol, pero no puedo, ya lo tengo asumido [...] (Tarragona, febrero 2014)

Los síntomas de la esquizofrenia no parecen ser el problema más importante, aunque, como la mayoría de los informantes, expresa que estos le causan mucho dolor y sufrimiento. Mientras que los síntomas parecen ajenos hasta que «le vienen», otras consecuencias las vive como algo que le afecta personal y socialmente, algo de lo que no es fácil desprenderse, a diferencia de los «malos pensamientos» que parece controlar, pero que la han limitado:

[...] Sin esto yo hubiera llegado más lejos... hubiera seguido estudiando, hecho un máster. Estoy bien donde estoy, pero sé que hubiera sido mucho más sin esta enfermedad [...]. (Irene en grupo focal familiar, Tarragona, febrero de 2014)

Las consecuencias físicas y sociales son las que más han mermado su capacidad de hacer y su mundo de posibilidades. No se trata solo del cuerpo de 
Irene, sino de lo que el cuerpo de Irene puede hacer según las limitaciones que ella misma encuentra a partir de su problemática, su entorno y su mundo de vida. La acción de Irene se ve limitada cuando quiere extenderse más allá de su cuerpo. Como el de Antonella, el cuerpo de Irene no acaba en lo cutáneo, sino que se extiende al afuera, a lo que la rodea, y es ese ambiente el que merma las condiciones de posibilidad para la acción. Irene tiene un escenario de posibilidades mucho más amplio del que solemos encontrar en personas diagnosticadas de esquizofrenia. Sabe valorarlo, así como también sabe qué debe hacer para conservarlo. Irene ahora tiene el control, ha pedido a su dietista regímenes más lentos y, si tiene sensaciones raras, come mejor o más abundante, actúa desde una objetivación propia de sus sensaciones.

Cuando Irene habla de la medicación psiquiátrica ubica el problema mental en el cuerpo; explica que, si bien percibe que las paranoias suceden en la geografía mental, las causas y las consecuencias se trasladan al cuerpo en forma de efectos adyacentes, como el excesivo cansancio, que la obliga a interrumpir su jornada laboral para escaparse a hacer minisiestas en su coche; una estrategia de autoatención (Menéndez, 1984), una forma de cuidarse y atenderse fuera del modelo médico hegemónico, e incluso, fuera del sistema de normas de su trabajo. Acude a terapias alternativas que la relajan y la hacen sentir bien emocional y anímicamente. Aunque es muy disciplinada con su tratamiento psiquiátrico, se ha apoderado de algunas cosas y ha hecho suyas las cuestiones relacionadas con la dieta y el manejo del estrés. Ha capturado algunas experiencias corporales y actúa de forma «clandestina» al sistema experto, y encuentra así un mejor estar. Hacer propias las experiencias del cuerpo supone descolocarse, desubicarse de un modelo y ampliar el abanico de posibilidades de acción.

\subsection{María del Mar}

María del Mar tiene 47 años y está diagnosticada de trastorno límite de la personalidad. Puede explicar lo que le sucede con gran reflexividad y una capacidad de análisis de las experiencias muy interesante, pero fuertemente influenciada por el psicologicismo que nos rodea:

[...] En principio no llegué a ver esto como una enfermedad, aunque mi madre se la pasaba diciendo: eso lo heredó de su padre y hay que averiguar qué enfermedad tenía su padre. Y siempre se lo pasaba en eso, pero a mí no me 
preocupaba el tener una enfermedad, porque yo siempre creí mucho en la Psicología y en la Psiquiatría, yo quería estudiar eso. Si yo tengo una enfermedad, no es más que un nombre, y se trata de aprender a vivir con ello [...]. (Barcelona, diciembre de 2013)

Presta mucha atención a su cuerpo y a lo que este le indica, aunque, mediante las observaciones, las entrevistas, las largas charlas off-recording, llamadas de teléfono y correos electrónicos, María del Mar aún no se ha apoderado de su cuerpo y, de alguna manera, tampoco de su acción. Desde hace un año ha entrado en una cotidianidad atravesada por dinámicas muy conflictivas en las que se ven perjudicadas sus relaciones personales. No se siente cómoda en ningún espacio, ni en su casa, ni en pisos asistidos, ni en los ingresos o internamientos, e incluso se ha enfrentado con amistades de una asociación en la que era asidua y se sentía acogida. Tras varios meses de trabajar con ella, no solo como investigadora-investigada, sino habiendo generado una relación más personal —en la que me he visto más de una vez como «acompañante» en algunos de sus problemas-, he visto que actúa, construye y se extiende más allá de la denominación de su patología, desde una subjetividad atrapada en la identidad de enferma:

[...] Estuve muchos años viviendo con mi madre en habitaciones alquiladas, una cantidad de cosas, mucha culpa, mucha inestabilidad, imagínate una TLP viviendo en ambientes inestables, cuando la inestabilidad es su fuerte, o su debilidad ¿me entiendes? Que si mi padre supuestamente venía, y lo iba a conocer y resulta que sí, que no, que sí [...]. (Barcelona, diciembre de 2013)

[...] Los TLP tenemos tendencias suicidas. A veces caemos en depresivos de una forma tan rápida, y en esos fondos depresivos se nos viene enseguida la idea de la muerte, con una facilidad incré́ble, y es como si ya no importara nada, y a mí me caga, porque mi padre murió suicidado, y a mí me da terror terminar como él [... . (Barcelona, diciembre de 2013)

[... ] me limita en el amor, creo que el hecho de tener una enfermedad psiquiátrica y de tomar tanta medicación, no solo está el problema de la barriga, sino que pienso que no cualquiera se mete, se echa al carro de meterse con una persona así... y eso es lo más cruel, y es lo que más yo, sentí con X que yo dije [... ] qué coño se va a estar involucrando $X$ con una enferma mental, mucho más un TLP, que por internet la llaman la lepra de las enfermedades mentales... 
así la llaman, con toda la medicación que yo tomo... Yo después lo vi como que, tía, de la tierra al cielo de distancia de X, y me sentí muy estúpida por simplemente osar a fijarme en X, y eso jode mucho. Jode mucho. Pero sí tengo muy claro, y a veces, pero no lo hago en son de... quiero que se entienda, no es en son de insulto, porque yo me incluyo en ellos, y es que somos subnormales... pero no lo hago por maldad [risas], sino como una manera de hablar, pero yo no pienso hacer mi vida al lado de un subnormal, o sea, metiéndome en el término subnormal, yo no quiero hacer mi pareja con una persona diagnosticada, y que vayamos a los talleres y a un piso protegido, yo aspiro a mucho más para mí. Y si no puedo tener eso, moriré en el intento, eso yo lo tengo muy claro [...]. (Barcelona, noviembre de 2013)

[... yo es que medito... medito mucho y me autoanalizo, y hago análisis de lo que me está pasando, de lo que está pasando a mi alrededor y tal, hasta que termino llegando a la conclusión de que todo está en mí, de que todo depende de mí, de mi actitud ante la vida, de sentirme como yo me quiera sentir, y así empiezo a agarrar ánimos y ánimos y otra vez [...]. (Barcelona, febrero de 2014)

[...] pero bueno, los TLP siempre buscamos un culpable, enfermamos a la familia, a los padres, culpamos a la madre de todos nuestros males, eso es lo que dicen de los TLP y yo ya quiero parar de culpar, yo lo que quería es vivir, ya no quiero culpar, yo no quiero buscar de quién fue, yo ya decidí pasar de la familia de mi madre, por completo, ellos no me llaman y yo ni llamarlos, ni pensar, pasar olímpicamente, es coger yo mi propia familia [... ]. (Barcelona, febrero de 2014)

María del Mar desarrolla dos formas diferentes dentro de la figura de enfermo total. Una que sirve como justificación a sus actos al concebirse como una persona enferma. Ella es una TLP, tal y como se describe, lo que le sirve como argumento para un descargo de responsabilidad. La enfermedad la llevaría a culpar a los otros por lo que le sucede - las idas y venidas que su madre llevó a cabo durante su infancia-. Los pensamientos suicidas son causados por la sintomatología, y los sentimientos de culpar a otros no provienen de ella en sí misma, sino de la enfermedad. Por otro lado, el TLP la limita — en el amor y en el trabajo-, lo que le genera hostilidad no solo hacia sí misma, sino también hacia otros diagnosticados de este u otros trastornos. 
María del Mar se siente culpable por el sufrimiento que sus comportamientos ocasionan a otras personas. Por otra parte, la dependencia que tiene con personas de espacios asociativos la han llevado a perder a esas personas por la descarga de responsabilidad y demanda sistemática que ejerce, viéndose envuelta en situaciones conflictivas e incluso agresivas. Esto vuelve a llevarla a la culpa. Hace un proceso con tres fases diferenciadas que siguen siempre el mismo patrón: cuando las cosas son recientes - conflictos con la madre o con amistades - María del Mar descarga las responsabilidades en los otros. En el segundo estadio del proceso la invade el sentimiento de errar constantemente, cree cometer una serie de comportamientos que no sabe cómo enmendar y se sume en un proceso depresivo y angustioso. La tercera fase se produce cuando encuentra en el TLP una especie de chivo expiatorio que, por un lado, la reconforta por la desresponsabilización, y por otro, le genera sentimientos de rechazo con ella misma y con otros diagnosticados.

Este proceso por el que pasa María del Mar concluye en ubicarse con cierta comodidad en la identidad de enferma. Este lugar que asume acaba por mermar - y cuando no, bloquear - su autonomía en términos de conseguir o alcanzar los objetivos o proyectos que se había propuesto en un principio, como explica off-recorder. Si bien María del Mar tuvo momentos en los que describía su cotidianidad desde la autonomía, no alcanzar los objetivos que se propone la hunde y le genera un sufrimiento enorme, porque va más allá de la autonomía en términos de saber hacer la compra, gestionar su dinero o mantener la rutina en las labores de la casa. La autonomía que ella ve mermada al pasar por este proceso circular, una y otra vez, es la que ella describe como psicológica, marcando la diferencia entre esta y la autonomía física o personal. Cuando María del Mar explica esta autonomía psicológica — sin hacer referencia a ella misma, sino hablando de forma generalizada, aunque parece explicar su propio proceso-, esboza de forma abstracta las trabas y bloqueos que ella misma experimenta en sus relaciones personales, sobre todo con su madre:

[...] Tantos años nosotras con ese enganche de dependencia, y ella necesitar que yo dependa de ella y esa cuestión, pues, de alguna manera, ella, yo creo que teniendo esa necesidad interna, no es más que miedo ¿no? A veces las necesidades no son más que un terrible miedo, y yo creo que este, yo creo, dentro de esas necesidades de sentirme que dependía de ella por miedo a la soledad, a la vez la terminaba dejando más sola ‘no? Porque no tienes el cariño, que 
realmente no es cariño... porque la adoro, pero no tienes la compañía que realmente necesitas [...]. (Barcelona, diciembre de 2013)

Cuando conocí a María del Mar estaba viviendo, hacía escasos meses, en un piso asistido y se había independizado de su madre. Por diferentes circunstancias relacionadas con la convivencia, discusiones y enfrentamientos con sus compañeras y con las educadoras llevaron al intento de un internamiento involuntario por parte de estas últimas. Además, algunos conflictos en un espacio asociativo en el que era muy activa ocasionaron que María del Mar tuviera que abandonar el piso, la asociación y volver a vivir con su madre. La dependencia mutua que tiene María del Mar con su madre la sume en un círculo en el que ve fuertemente limitadas su autoestima, autonomía y capacidades de actuar.

\section{Conclusiones}

Tanto Antonella como Irene son muy activas en su vida social, trabajan, son muy autónomas y no viven con su familia de origen. Existen pocas diferencias entre ellas respecto a las formas de relacionarse con la enfermedad y respecto a los otros.

Antonella es parte de una asociación que le ha servido para ser crítica con el sistema médico y para militar contra el estigma sobre las enfermedades mentales. A pesar de haber vivido limitaciones por su diagnóstico, principalmente a nivel social, esto ya no le importa porque ha ganado otras cosas. Ya no se avergüenza de su diagnóstico porque «no está sola». El sentido colectivo y poder actuar desde la resignificación de la locura, me dice, la ha hecho ser mucho más tolerante y comprensiva con las personas, aceptar la heterogeneidad con más facilidad y valorar las pequeñas cosas de la vida. Ha pasado a ver su problema como algo que no es solo de ella, sino que también lo tienen los demás: «Es problema suyo si no entienden tu realidad» me decía en una ocasión. Sentirse parte de un colectivo que actúa en conjunto le permite superar el estigma comprendiendo que ella es mucho más que un diagnóstico. No teme hablar de su problema, porque este lo tiene también el afuera. Eso la ayuda a construir relaciones en las que el problema es compartido y en que ambas partes deben esforzarse para la interacción o la relación y no ser solo ella quien intenta encajar.

Irene es una mujer con una gran autonomía y capacidad de acción, aunque aún oculta su diagnóstico porque «no puedes decirle a nadie lo que tienes, 
solo a las personas más allegadas». Se representa como alguien que tiene una enfermedad, pero no como enferma. Aún tiene una serie de limitaciones que podrían, probablemente, borrarse o reducirse si encontrara un cuerpo colectivo que la acoja y donde pudiera desarrollarse como en casa, por ejemplo, donde pregunta a su madre si los pensamientos que tiene son reales o no porque la «ayuda a razonar qué cosas son de la realidad y qué cosas no». Esto la tranquiliza, es una práctica habitual en Irene que la ayuda a «razonar juntas la paranoia». Sin embargo, ni en sus salidas con amigas, ni en el trabajo, ni en las clases de cocina o en el curso de inglés Irene puede preguntarle a la gente si los pensamientos que tiene en un momento dado son reales. Es consciente de las limitaciones que aún soporta y le genera un gran malestar. No ha encontrado un espacio en el que poder desplegar su subjetividad o poder ser sincera en relación con las cosas que siente y percibe vinculadas a la sintomatología de la esquizofrenia o los malestares emocionales y sociales que le provoca. Solo se siente cómoda con su madre y el psiquiatra para hablar del tema, con nadie más. Esto genera unos niveles de estrés en la madre que a veces es muy difícil de gestionar por la carga de responsabilidad que conlleva.

Antonella e Irene han hecho propios sus cuerpos, viven el dolor de formas diferentes, pero muy suyas y particulares. Estos casos nos muestran que el problema no radica solo en la capacidad de cada uno de hacer propias las experiencias del cuerpo, sino que, simultáneamente, el mundo de vida también debe ser agenciado porque no escapa a la experiencia corporal, sino que forma parte de esta. Para hacer propio el mundo de vida es necesario que este acomode y facilite el escenario para que puedan hacerlo. Formar parte de un cuerpo colectivo puede resultar productor de agency y, sobre todo, productor de espacios de posibilidad para desarrollarlo y apropiarse del mundo de vida.

Por su parte, María del Mar describe lo que le aqueja como sensaciones, emociones, sentimientos, sufrimiento y muchísimo dolor. Habla desde lo preobjetivo en muchas ocasiones, sin embargo, pareciera no lograr salir de comportamientos del tipo pain behaviour, un intento de comunicar la experiencia misma del dolor o los afectos, el sufrimiento, moralización u otras ideas relacionadas con la experiencia del dolor (Jackson, 2004). Comportamientos que reflejan un profundo malestar emocional, pero que recaen siempre, descritos $y$ explicados por ella misma, en la patología. Si bien las significaciones y simbolizaciones del dolor que padece muchas veces escapan al modelo hegemónico, 
estas ideas que manifiesta a través de la palabra parecen no pasar y no sedimentarse en el cuerpo. Las acciones que comete se ven encerradas en la patología. Muchas veces tiene un discurso especialmente autorreferencial, magnificador de sus cualidades positivas como negativas y se ve envuelta en una justificación de sí misma encasillada en la enfermedad ubicua. A veces sale de esta identidad, sobre todo cuando habla de sus deseos y aspiraciones de cara a un futuro que nunca llega porque siempre recae en lo mismo. De alguna manera ha caído en una circularidad interpretativa (Martínez-Hernáez, 2009) propia, en la que significa el dolor siempre desde la identidad de TLP y justifica sus acciones a través del diagnóstico. Tiene grandes deseos de hacer cosas, de proyectar las capacidades que hemos ido descubriendo a lo largo de nuestras conversaciones y de convertirlas en hechos, pero expresa una gran frustración cuando no consigue sus objetivos o se destruyen por su dinámica conflictiva. Se mueve en la simultaneidad de descifrar el origen de sus dolores fuera de la enfermedad, pero los reinserta en los síntomas del TLP y actúa en forma de enferma total. A veces logra salir de esa identidad en forma de aspiraciones, pero no llega a consumarlas. La información que María del Mar tiene y reflexiona no logra pasar por su cuerpo para materializarse en acción.

La enfermedad es experimentada a través del cuerpo, y este no es simplemente un objeto físico, sino una parte esencial del yo (Good, 1994). Cuando el trastorno mental sucede, no solo cambian cosas en el sujeto, sino que cambia el mundo de vida, las relaciones, la cotidianidad. Entender la enfermedad mental desde la idea de dolor crónico es un modo de poner de relieve como la experiencia de la enfermedad se extiende a las diferentes facetas y roles de la vida. Al mismo tiempo, el sufrimiento que desencadenan los síntomas de la patología, así como sus consecuencias en las relaciones y sociales, afectan también a las personas de alrededor.

La identidad de enfermo, y las imposibilidades que esta presenta, es construida también por esa distinción popular entre el mundo de la realidad objetiva y el de la experiencia subjetiva que provoca estragos en el tratamiento del dolor en el cuerpo social y en el cuerpo político (Good, 1994), cuando el sujeto se ve inmerso en un mundo que ha cambiado y que no le presta las mismas oportunidades que a los no diagnosticados. Las narrativas escogidas muestran cómo el dolor y el sufrimiento es vivido en el cuerpo, cómo esas sensaciones que entendemos como preculturales pueden ser resignificadas desde otros lu- 
gares cuando el sujeto las hace propias. El trastorno mental suele adherirse a la geografía mental y pocas veces pensamos las consecuencias «corporales» en tanto son y construyen el yo.

El dolor crónico es crónico porque permanece. El sufrimiento de los afectados no culmina en el paliativo de la medicación, o en un programa de reinserción laboral. Las aflicciones se perpetúan en las relaciones afectivas, en las posibilidades anuladas o mermadas, en la ausencia de comprensión, o en el sentirse fuera de lo social: ser siempre el otro. El hecho de poder ser sin preceptos morales o sociales, ya sea en casa, en un espacio colectivo o en el afuera, renueva, y estos cambios se hacen manifiestos en la acción que el sujeto puede cometer. Se abre el abanico de la capacidad de acción y se reconstruye un agency que habría sido acuartelado por el diagnóstico. Cuando el mundo de vida entra en el laberinto del pain-full world, surge la necesidad de detectar el pain behaviour para poder trabajarlo y construir terapéuticas que muevan el eje, que dinamicen el estatismo y el estancamiento en la identidad de enfermo que es experimentada desde el diagnosticado y desde aquellos que lo acompañan en lo cotidiano. Experimentar el dolor del rechazo, la incomprensión y el estigma es vivido en carne propia, pero también en carne amada.

Resignificar para una nueva acción o accionar para resignificar supone un nuevo cambio en el mundo de vida de los afectados. Por ello, la etnografía de la experiencia (Kleinman, Kleinman, 1991) es de fundamental importancia en nuestra labor como antropólogos, sobre todo cuando entendemos la etnografía como dialógica, ya que por su marco epistémico puede resultar como instrumento para la creación de políticas interculturales de promoción para la salud a partir de fundamentos de este método de conocimiento como la reflexividad, el relativismo metodológico y la relación dialógica entre saberes expertos y profanos (Martínez-Hernáez, 2010). «Cuando el sufrimiento no se alivia, tampoco el relato adquiere autoridad, y el yo se ve amenazado de disolución» (Good, 1994: 223). Prestar nuestra metodología, que permite un espacio de posibilidad horizontal de escucha y diálogo, puede resultar terapéutico en tanto que podría calmar aquellos sufrimientos devenidos de la deslegitimación de las voces afectadas. 


\section{Bibliografía}

American Psychiatric Association (2013). Diagnostic and statistical manual of mental disorders (DSM-5 ${ }^{\circ}$ ), American Psychiatric Pub.

Carel, H. (2011). "Phenomenology and its application in medicine». Theoretical medicine and bioethics, 32(1), pp. 33-46. Disponible en: <http:// www.ncbi.nlm.nih.gov/pubmed/21103940> [Consultado el 15 de diciembre de 2014].

Comelles, J. M.; Martínez-Hernáez, À. (1994). «The dilemmas of chronicity: the transition of care policies from the authoritarian state to the welfare state in Spain». International Journal of Social Psychiatry, (40), pp. 283-295.

Correa Urquiza, M. et alii (2006). «La evidencia social del sufrimiento: salud mental, políticas globales y narrativas locales». Quaderns de l'Institut Català d'Antropologia, (22), pp. 47-69.

Correa Urquiza, M. (2009). Radio Nikosia: La rebelión de los saberes profanos. (Otras prácticas, otros territorios para la locura). Universidad Rovira i Virgili.

Csordas, T. J. (2004). Embodiment and Experience: The Existential Ground of Culture and Self. New York: Cambridge University Press.

- (2002). Embodiment as a Paradigm for Anthropology. New York: Palgrave Macmillan.

DiGiacomo, S. (1995). «The case: A narrative deconstruction of diagnostic delay'» Second Opinion, 20 (4 [April]), pp. 21-35.

- (2013). «La metáfora como enfermedad: dilemas posmodernos en torno a la representación del cuerpo, la mente y el padecimiento,» En MArtínezHernáez, À.; Masana, L.; DiGiacomo, S. M. Evidencias y narrativas en la atención sanitaria: Una perspectiva antropológica, p. 35.

Good, B. J. (1994). El cuerpo, la experiencia de la enfermedad y el mundo de vida: una exposición fenomenológica del dolor crónico. En Medicina, Racionalidad y Experiencia. Una perspectiva antropológica. Barcelona: Edicions Bellaterra.

Kleinman, A.; Kleinman, J. (1991). «Suffering and its Professional Transformation: Toward and Ethnography of Interpersonal Experience.» Culture, medicine and psychiatry, 15(3), pp. 275-301. 
Lupton, D. (1999). Risk and Sociocultural Theory: New Directions and Perspectives. Lupton D., ed., Cambridge: Cambridge University Press.

Martínez-Hernáez, À. (2010). «La etnografía como dialógica: hacia un modelo intercultural en las políticas sanitarias.» En F. Checa y Olmos, A.; Arjona Garrido; J. C. Checa Olmos (eds.), Transitar por espacios comunes. Inmigración, salud y ocio. Barcelona: Icaria Antrazyt, pp. 57-84.

- (2009). «Más allá de la rehabilitación psicosocial. Metáforas de exclusión y tareas de inclusión.» Cad. Bras. Saúde Mental, 1(1).

Masana, L. (2013). El Temps Del Mal. L’Experiència I La Gestió De La Cronicitat En Adults. Universidad Rovira i Virgili.

Melián, E. M. (2012). «La experiencia mística durante el climaterio: un acercamiento desde la endocrinología antropológica,» Investigaciones Feministas, (4), pp. 323-334.

Menéndez, E. (1984). «El modelo médico hegemónico: transacciones y alternativas hacia una fundamentación teórica del modelo de autoatención en salud.» Arxiu d'Etnografía de Catalunya, 3, pp. 84-119. Disponible en: <http://www.antropologia.urv.es/revista/index.php/aec/article/viewArticle/124> [Consultado el 20 de diciembre de 2014].

Organizacion Mundial de la Salud (1992). Décima Revisión de la Clasificación Internacional de Enfermedades: Trastornos mentales y del comportamiento: descripciones clínicas y pautas para el diagnóstico.

París Serra y Comelles, J. M. (1998). «Acerca de la construcción sociocultural de la cronicidad.» Trabajo social y salud, 29, pp. 315-324.

Rodríguez-Zafra, M. (2007). Estados de conciencia y crecimiento. F. Rodríguez Bornaetxea (ed.), Barcelona: Editorial Kairós.

Schütz, A. (1967). The Phenomenology of the Social World, Evanston, IL: Northwestern University Press.

Wikan, U. (1990). Managing turbulent hearts: A Balinese formula for living. University of Chicago Press. 